\title{
Maternal Periodontal Disease and Pregnancy Outcomes
}

\author{
Fathi M Sherif* \\ Department of Pharmacology and Clinical Pharmacy, Libya \\ *Corresponding author: Fathi Mohamed Sherif, Department of Pharmacology, Libya \\ Submission: 此 March 05, 2018; Published: 制 March 29, 2018
}

\section{Editorial}

Preeclampsia is a disorder of uncertain etiology of human pregnancy. It defines by high blood pressure and high protein in urine. If it left without treatment, it will change to eclampsia which leads to high rates of morbidity and mortality [1]. Its prevalence is beyond $10 \%$ and is the main maternal death. If preeclampsia occurs before 32 weeks of gestation, it is considered as earlyonset and is more likely of high morbidity rate. Preeclampsia is associated with multiple maternal and fetal adverse effects [2]. Periodontal disease (PD) is a chronic infection of gingival with dental supportive structures caused by periopathogen bacteria. PD is identified by extensive damage to dental supportive structures as alveolar bone accompanied by forming pocket and gingival recession. This involves of direct tissue damage as a result of bacterial plaque and of indirect by bacterial effects on the immune system [3]. Inflammation and infection play a role in the pathogenesis of preterm birth through various path physiological mechanisms. It occurs in $15 \%$ of women and is more in pregnancy which specified by clinical attachment loss. PD is either gingivitis or periodontitis. Interestingly, published data have indicated that preeclampsia cases have significantly higher attachment loss and gingival recession than control cases [4,5].

Periodontitis was assumed as a risk factor for preeclampsia, since infection is involved in etiology and pathogenesis of preeclampsia and as a factor for adverse pregnancy outcomes [5]. Maternal periodontitis is associated with increased threat of induced preterm birth and low birth weight [6]. Thus, PD is a public health problem since it is independent risk factor for adverse pregnancy outcomes; however, it is preventable and curable. The association between PD and preeclampsia has recently been in debate [7]. Periodontitis induced by gram-negative anaerobic bacteria that causes elevations of pro inflammatory mediators. The fetal-placental unit in woman with progressive periodontitis is exposed to inflammatory mediators that participate preterm labor and delivery $[4,6,8]$. For example, aggressive periodontitis is correlated with elevated levels of interleukin- 6 in saliva. When elevated in the serum or amniotic fluid, interleukin- 6 predicts preterm labor and delivery. The association between progressive periodontitis and risk for preterm before 37 weeks has significantly been stated in preeclampsia women. Transmission of bacteria from mouth to placenta and induction of inflammation may harm the endothelium of placental vessels, thus, producing preeclampsia. Periodontal infection causes transient and low- grade bacteremia and end toxemia which promotes inflammatory and immune responses as well as elevated circulating C-reactive protein in PD inducing adverse pregnancy outcomes. Other inflammatory mediators from inflamed periodontal tissue as PGE2 and cytokines inducing inflammation that causes injury to placenta as well as preeclampsia. In general, similarities between preeclampsia and atherosclerosis are stated [9]. Thus, atherosclerosis is associated with endothelial dysfunction and seems it is associated with periodontitis. Other epidemiologic factors as obesity, hypertension and black race are also contributed. One of the reasons for abnormalities in endothelial function is the presence of severe inflammatory responses. The possibility of long-term exposure to inflammatory mediators and/or bacteria is associated with disease progression and necessary to adversely affect birth outcomes. It should also be mentioned that repeated periodontal therapy may activate immune responses, which in turn affect pregnancy outcomes. This may occur through increased TLR-4 expression on placental trophoblasts that is associated with preeclampsia but not preterm labor. The reasons may be of an abnormal thromboplastic invasion of uterine vessels, immunologic mismatched between mother and child, lack of mother's proper compatibility with cardiovascular and inflammatory changes of pregnancy, diet and genetics. However, treatment of PD during pregnancy is safe and is not contraindicated in pregnancy. Thus, control of oral diseases improves the woman's quality of life and is a potential aspect to reduce the transmission of oral bacteria from mothers to children.

\section{References}

1. Steegers EAP, von Dadelszen P, DuvekotJJ, Pijnenborg R (2010) Preeclampsia. Lancet 376: 631-644.

2. Golsenberg RL, Culhane JF, Iams JD, Romero R (2008) Epidemiology and causes of preterm birth. Lancet 371(9606): 202-207.

3. Tonetti MS, D'Aiuto F, Nibali L, Donald A, Storry C, et al. (2007) Treatment of periodontitis and endothelial function. N Engl J Med 356(9): 911-920. 
4. Shetty M, Shetty PK, Ramesh A, Thomas B, Prabhu S, et al. (2010) Periodontal disease in pregnancy is a risk factor for preeclampsia. Acta Obstet Gynecol Scand 89(5): 718-721.

5. Ruma M, Boggess K, Moss K, Jard H, Murtha A, et al. (2008) Maternal periodontal disease, systemic inflammation and risk for preeclampsia. Am J Obstet Gynecol 198(4): 389.el-5.

6. Pitiphat W, Joshpipura KJ, Gillman MW, Williams PL, Douglass CW, et al. (2008) Maternal periodontitis and adverse pregnancy outcomes. Community Dent and Oral Epidemiol 36(1): 3-11.

7. Ferguson E, Hansen WF, Novak KF, Novak J (2007) Should we treat periodontal disease during gestation to improve pregnancy outcomes? Clin Obstet Gynecol 50(2): 454-467.

8. Manau C, Echeverria A, Agueda A, Guerrero A, Echeverria JJ (2008) Periodontal disease definition may determine the association between periodontitis and pregnancy outcomes. J Clin Periodontol 35(5): 385397.

9. Chopra R, Patil SR, Mathur S (2012) Comparison of cardiovascular disease risk in two main forms of periodontitis. Dental Research Journal 9: 74-79.

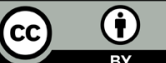

Creative Commons Attribution 4.0 International License

For possible submissions Click Here

\section{Submit Article}

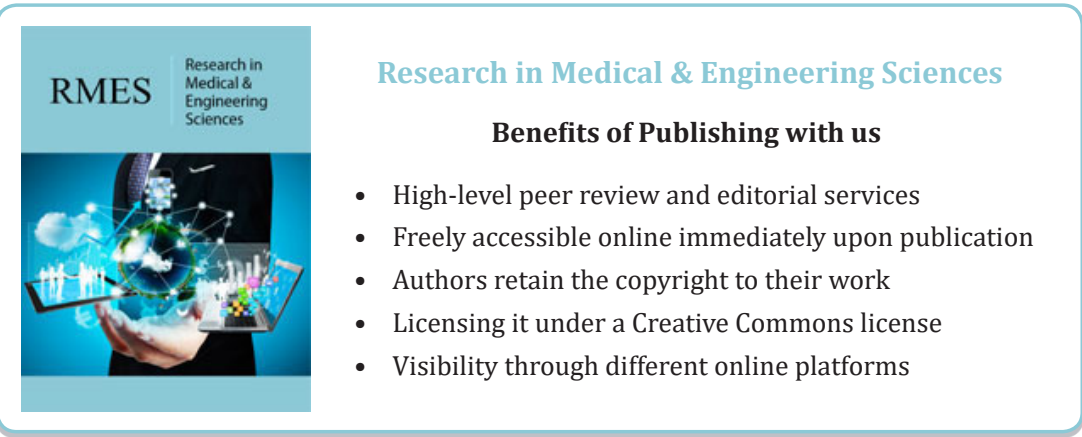

